\title{
PROCESSOS DE DESESTABILIZAÇÃO ATMOSFÉRICA E CONVECÇÃO PROFUNDA NO SEMIÁRIDO BRASILEIRO
}

\author{
Magaly F. Correia ${ }^{1,}$; Milla N. M. Costa ${ }^{2}$; Alexsandra Barbosa Silva ${ }^{2}$; M. Regina da Silva \\ Aragão $^{1}$; Jaqueline N. de Queiroz ${ }^{2}$ \\ ${ }^{1}$ Professora DCA-UFCG; ${ }^{2}$ Aluna de pós-graduação - UFCG \\ *magaly@dca.ufcg.edu.br
}

\section{RESUMO}

O desenvolvimento deste trabalho tem como objetivo identificar mecanismos importantes no processo de desestabilização atmosférica e evolução da atividade convectiva. $O$ grau de instabilidade atmosférica aliado ao teor e transporte zonal de umidade na baixa troposfera foi identificado através de uma análise fatorial em componentes principais como os principais fatores na ocorrência da convecção profunda e chuva intensa observadas em janeiro de 2004 no semiárido brasileiro.

\begin{abstract}
The objective in developing this work is to identify important mechanisms in the process of atmospheric desestabilization and convective activity evolution. The degree of atmospheric instability combined with moisture content and transport in the lower troposphere is found by means of a factorial analysis by principal components to be the main factors in the occurrence of deep convection and intense rainfall as observed in January 2004 in the Brazilian semiarid.
\end{abstract}

\section{INTRODUÇÃO}

Temporais, formação de cheias e grandes inundações em bacias hidrográficas no semiárido brasileiro ainda são abordadas como episódios raros. Contudo, estudos sobre eventos meteorológicos extremos indicam que padrões atmosféricos estabelecidos em períodos de atuação da ZCIT (zona de convergência intertropical) e/ou de VCAN (vórtices ciclônicos de altos níveis) são favoráveis ao desenvolvimento de sistemas convectivos (SC) intensos. De acordo com Wulfmeyer et al. (2006), o aquecimento e a elevação da umidade nas camadas próximas da superfície, a convergência nos baixos níveis da troposfera e o transporte diferencial de temperatura na média troposfera estão entre os principais mecanismos de desenvolvimento da convecção profunda.

A variabilidade de processos físicos em diferentes escalas modifica as propriedades termodinâmicas ao longo da vertical na área em que ocorre a convecção. Neste sentido, a compreensão de mecanismos responsáveis pela inicialização e intensificação da atividade 
convectiva representa um dos aspectos importantes em investigações sobre a gênese e desenvolvimento dos SC.

\section{METODOLOGIA}

O mês de janeiro de 2004 foi selecionado para análise por incluir dias com atividade convectiva que varia de leve a severa e desenvolvimento de convecção profunda, com formação de cheias e inundações em regiões semiáridas da bacia hidrográfica do rio São Francisco (Correia et al., 2012). Dados de sondagens realizadas em Petrolina PE, observações de superfície e imagens de satélite foram utilizados como principal fonte de informações. A análise fatorial por componentes principais ACP no modo $\mathrm{P}$ foi escolhida como método estatístico para explicar a estrutura de dependência entre as variáveis meteorológicas dominantes e relação com fatores específicos.

\section{RESULTADOS}

Os três primeiros fatores obtidos com a ACP explicam 94,5\% da variância dos dados originais. Variáveis com cargas fatoriais maiores ou iguais a 0,7 são destacadas na Figura 1.
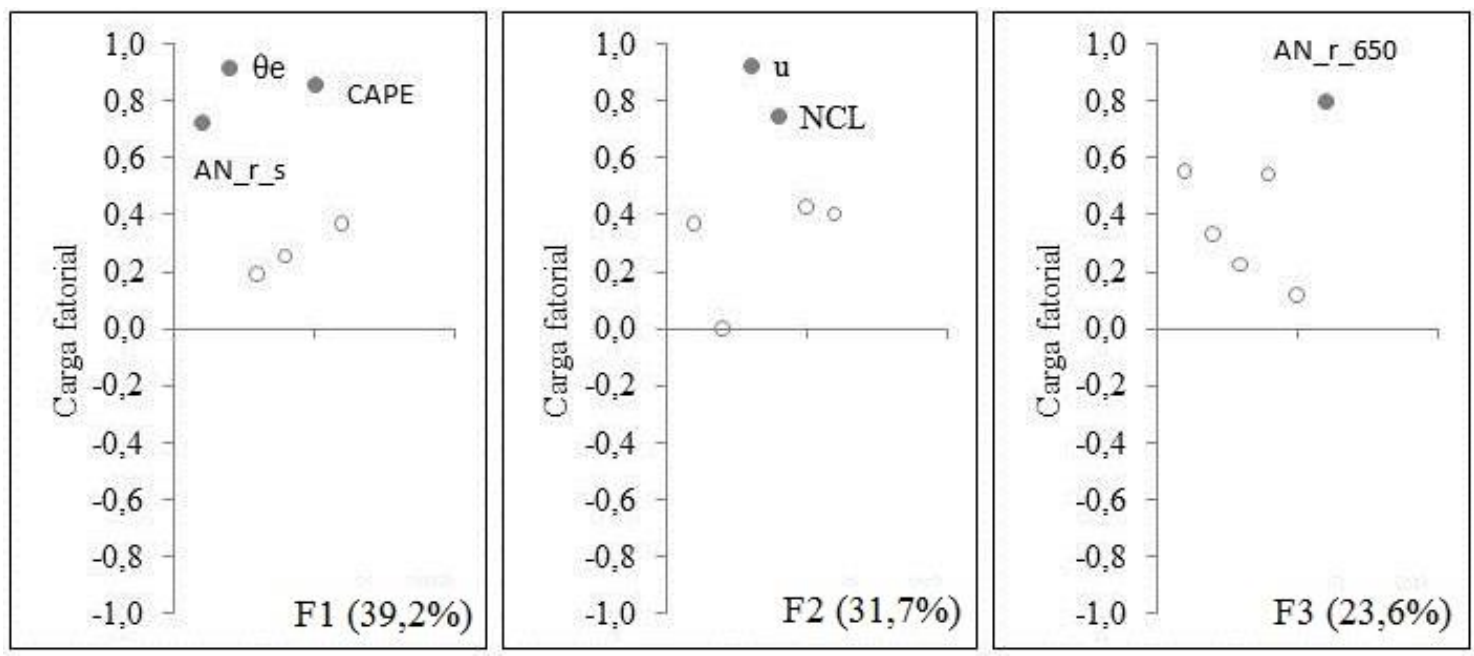

Figura 1. Composição das variáveis por fator (cargas >0,7).

A relevância da interação entre processos dinâmicos e termodinâmicos na modulação da convecção é clara em função da associação entre as variáveis $\theta \mathrm{e}$ (temperatura potencial equivalente), CAPE (energia convectiva disponível) e AN_r_s (anomalia da razão de mistura em superfície) no F1. Este resultado mostra que o grau de instabilidade atmosférica é um 
fator determinante para o início da atividade convectiva. Entretanto, o teor de umidade nos baixos níveis representa o componente fundamental no desenvolvimento da convecção profunda e precipitação intensa.

A relação positiva entre u (componente zonal do vento em superfície) e NCL (nível de condensação por levantamento) observada no F2 indica que o transporte de umidade nos baixos níveis é importante no processo de formação das nuvens. O efeito deste mecanismo na estrutura vertical da atmosfera é evidente na seção vertical da anomalia de $\mathrm{r}(\mathrm{g} / \mathrm{kg})$ e evolução temporal das variáveis "u" e "NCL" apresentadas na Figura 2.



(a)

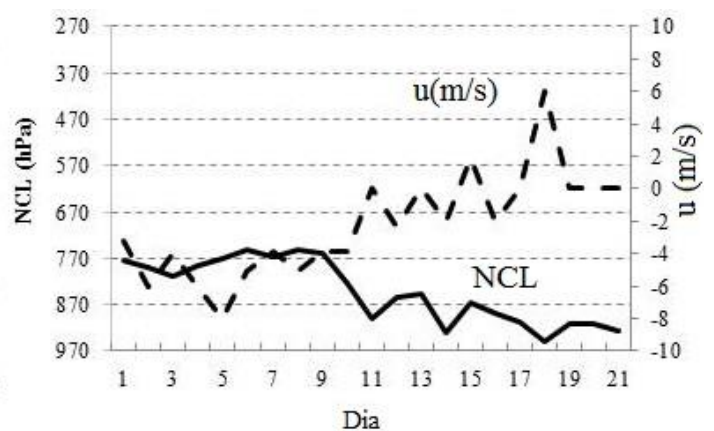

(b)

Figura 2. (a) Seção vertical da anomalia da razão de mistura r(g/kg), e (b) evolução temporal da componente zonal (u) em superfície e do nível de condensação por levantamento (NCL).

Escoamento predominantemente de leste, NCL mais alto e anomalias negativas da razão de mistura são características importantes observadas no período de atividade convectiva fraca (1 a 10 de janeiro). Ao contrário, a partir do dia 11 de janeiro, o vento é substancialmente mais fraco e de oeste. Diminuição progressiva do NCL, anomalias positivas de umidade, convecção profunda e chuvas fortes, representam propriedades marcantes deste período. Resultados semelhantes foram encontrados por Silva Aragão et al. (2007).

O terceiro fator F3 é responsável por $23,6 \%$ da variância total dos dados e mostra forte correlação com a variável AN_r_650 (anomalia de umidade em 650 hpa). Fluxo de ar potencialmente mais frio (quente) que o ambiente em níveis médios produz movimentos descendentes (ascendentes), originando mesoaltas (mesobaixas) na camada limite.

\section{CONCLUSÃO}

Os resultados permitiram concluir que mecanismos dinâmicos e termodinâmicos atuaram simultaneamente nos processos de liberação ou supressão da atividade convectiva no período 
analisado. Convergência de umidade nos baixos níveis em ambiente instável foi o fator preponderante para ocorrência da convecção profunda e, consequentemente, desenvolvimento ou inibição de SC intensos.

\section{BIBLIOGRAFIA}

Correia, M. F.; Gonçalves, W. A.; Silva Aragão, M. R.; Diniz, M. C. S. Mudanças na estrutura termodinâmica da atmosfera na presença de vórtices ciclônicos de altos níveis: Um episódio de precipitação extrema no semiárido brasileiro. Revista Brasileira de Geografia Física, v. 4, p. 877-890, 2012.

Silva Aragão, M. R.; Damião Mendes, M. C., Cavalcanti, I. F. A., Correia, M. F. Observational study of a rainy January day in the Northeast Brazil semi-arid region: Synoptic and mesoscale characteristics. Quarterly Journal of the Royal Meteorological Society, v. 133, p. 1127-1141, 2007.

Wulfmeyer, V. et al. COPS Science Overview Document. 2006. Disponível em http://www.unihohenheim. de/cops/further reading/further reading.htm. 